\title{
Transaksi Pembayaran T-Cash Dengan Dukungan Teknologi Berbasis Near Field Communications (NFC)
}

\author{
Agung Wibowo
}

\begin{abstract}
Abstrak - Makalah ini akan membahas mengenai T-Cash yaitu uang digital Telkomsel yang menjadi salah satu layanan digital lifestyle yang sedang dikembangkan oleh Telkomsel. Dengan lisensi dari Bank Indonesia, TCash kini hadir dengan teknologi Near Field Communication (NFC), yang dinamakan TCash TAP. Hal ini akan memberikan kemudahan dan pengalaman unik kepada pelanggan dalam melakukan transaksi. Layanan ini dapat digunakan di semua jenis ponsel baik feature phone maupun smartphone. TeknologiNFC dalam Tcash ini adalah pengembangan dari teknologi kartu Radio Frequency IDentification (RFID). Teknologi NFC pada handphone selangkah lebih maju daripada teknologi RFID dimana pada handphone ditanamkan NFC chip yang dapat bertindak sebagai kartu RFID dan juga sebagai reader sekaligus dengan radius jangkauan pendek (kurang dari $10 \mathrm{~cm}$ ). Teknologi NFC pada handphone betul-betul dapat menggantikan dompet dimana dapat mengeluarkan uang dan juga menerima uang dari dan ke sesama pengguna NFC. TCASH memberikan berbagai solusi untuk transaksi nontunai. Dengan mudah, pembayaran merchant favorit dengan berbagai promo, beli pulsa dengan harga terbaik, bayar tagihan, belanja online tanpa kartu kredit, kirim uang, dan masih banyak lagi.diharapkan akan menjadi teknologi yang sangat efisien dan efektif pada proses pembayaran.
\end{abstract}

Keywords : Pembayaran; transaksi; T-cash; near field communication

\section{PENDAHULUAN}

Perkembangan teknologi tak di pungkiri ikut mengubah kebiasaanmasyarakat, termasuk dalam aktivitas keuangan. Transaksi ekonomi yang dulu berawal dari sistem barter, yakni sistem pembelian dan penjualan barang dengan menukarkan dengan barang yang lain, kini berubah menjadi

Received: 5 Februari 2018; Revised: 1 Maret 2018; Accepted: 1 April 2018.

A. Wibowo., Jurusan Magister Sistem Informasi Fakultas Teknologi Informasi Universitas Kristen Satya Wacana - Salatiga (black.mikael@gmail.com). sistem uang yang menggunakan uang sebagai nilai ukur harga dari suatu barang. Namun sistem uang yang terjadi di masyarakat terasa masih ada kekurangan, seperti halnya ketidaknyamanan manusia ketika membawa uang dalam jumlah banyak karena mempertebal dompetnya, kesulitan dalam melakukan transfer uang karena harus bertemu langsung dengan penerima, kesulitan dalam pembayaran tagihan karena harus datang ke kantor tempat pembayaran tagihan, dll. Keadaan yang demikian membuat manusia semakin terpacu untuk membuat inovasi-inovasi baru untuk memberikan solusi dalam masalah tersebut. Seperti halnya PT.TELKOMSEL, perusahaan ini memberikan solusi untuk menyelesaikan masalah diatas dengan membuat sistem $\mathrm{T}$ Cash. T-Cash adalah sebuah layanan digital money di Indonesia yang dapat digunakan pelanggan Telkomsel untuk melakukan transaksi pembelian dan pembayaran secara digital dengan menggunakan ponsel di Merchant yang berlogo TCash.

Layanan pembayaran elektronik Tcash diluncurkan pada 2007 dan diperbarui dengan mengadopsi teknologi Near Field Communication (NFC) pada 2015. Dengan menggunakan TCash ini, orang tidak perlu lagi untuk membawa uang tunai yang mempertebal dompetnya ketika harus melakukan transaksi jual-beli di pasar. Karena uang sudah tersimpan dalam bentuk digital di server Telkomsel, sehingga orang cukup mengakses server tersebut melalui ponselnya masingmasing dengan melakukan request sejumlah uang yang diinginkan ke ponsel penerima, maka secara otomatis uang yang di-request tersebut akan masuk ke ponsel penerima. Tidak hanya itu, dengan T-Cash ini orang tidak perlu lagi pergi ke tempat pembayaran tagihan listrik, air dan telepon, karena cukup dengan ponsel dimanapun orang tersebut berada, dia bisa membayar tagihan-tagihan tersebut. T-Cash ini juga dilengkapi dengan teknologi pin, sehingga lebih aman dibanding sistem uang yang konvensional.

NFC adalah pengembangan dari teknologi Radio Frequency Identification (RFID) yang digunakan ke dalam perangkat handphone untuk memudahkan transaksi.NFC jika dilihat dari sudut pandang teknologi merupakan perpaduan dari smart card dengan smart phone, dimana teknologi ini tidak memerlukan kabel dan memungkinkan pengguna secara wireless atau menggunakan ponsel untuk melakukan pembayaran non-tunai. NFC dianggap sebagai perkembangan besar karena 
kemudahannya dalam interaksi antar perangkat yang berbeda.Selain mudah digunakan NFC, biaya NFC sangat terjangkau dan dapat melakukan seluruh transaksi pembayaran non-tunai, pengambilan data, sebagai identitas, kesehatan, dan banyak lagi keuntungannya. NFC memiliki sistem yang dapat diprogram secara langsung.

\section{KONSEP DASAR}

Alternative pembayaran melalui Mobile Money mulai banyak dipergunakan. Telkomsel adalah salah satu perusahaan telekomunikasi yang sudah memperkenalkannya melalui TCASH. New TCASH diluncurkan untuk menunjang gaya hidup digital pelanggan dan juga mendukung pemerintah Indonesia di dalam membangun Gerakan Nasional Non Tunai (GNNT) serta mempercepat inklusi keuangan. Layanan uang elektronik T-Cash telah mendapat izin penerbitan dari Bank Indonesia. Berbeda dengan pulsa, T-Cash dapat digunakan untuk berbagai transaksi seperti belanja, membayar tagihan, membayar merchant, isi pulsa, dan kirim uang.Telkomsel juga bekerja sama dengan Tim Nasional Percepatan Penanggulangan Kemiskinan (TNP2K) untuk studi kelayakan penggunaan uang elektronik TCASH dalam distribusi bantuan dan subsidi pemerintah. Harapannya, alternative cara bayar baru ini dapat memberikan akses keuangan yang nyaman ke berbagai kalangan masyarakat. Bukan hanya diperkotaan, tetapi juga pedesaan. Termasuk masyakarat yang belum terlayani oleh lembaga keuangan resmi (unbanked).TCASH kini hadir dengan teknologi Near Field Communication(NFC), teknologi tersebut merupakan perkembangan dari Radio Frequency Identification (RFID). Perkembangan NFC ini merupakan penggabungan antara ponsel yang dilengkapi dengan chipset NFC.Cukup dengan menempelkan sticker NFC ke ponsel, mengaktifkan layanan, dan pelanggan dapat melakukan 'TAP' di mesin NFC merchants. Transaksi TCASH pun sangat aman karena menggunakan 6 digit PIN.

TCash dengan teknologi NFC memiliki kemampuan yang lebih dalam sebuah ponsel, seperti melakukan transaksi pembayaran dengan mudah, dengan menghubungkankan antara perangkat yang memiliki NFC, dan tidak perlu digosok (contactless), hanya tinggal ditempelkan ketika melakukan transaksi pembayaran. NFC melakukan transaksi pembayaran yang lebih baik dari pada teknologi telepon selular (sms) [3]. NFC adalah teknologi komunikasi tanpa kabel (nirkabel) dengan jarak yang dekat. NFC telah didefinisikan dalam ISO 18092 dan sesuai dengan smart card dengan standar ISO 14443 [4]. NFC hanya dapat melakukan transaksi pembayaran contactless dengan jarak sekitar $10 \mathrm{~cm}$. Pelanggan Telkomsel bisa mengaktifkan layanan T-Cash dengan cara berikut ini:

- Aktifkan T-Cash dengan menghubungi $* 800 * 88 \#$ melalui perangkat mobile.

- Dapatkan stiker T-Cash di GraPARI terdekat.

- Tempelkan stiker T-Cash pada smartphone (disarankan untuk mematikan fitur NFC yang terdapat pada smartphone atau tempel stiker di bagian yang tidak menutupi area NFC).

- Customer service Telkomsel akan membantu pelanggan mengaktifkan nomor PIN T-Cash

- $\quad$ Stiker T-Cash akan aktif pada transaksi pertama
Jika layanan T-Cash sudah aktif, maka pelanggan dapat melakukan isi saldo T-Cash melalui berbagai cara, bisa melalui GrapaRi, ATM Bersama, atau gerai Indomaret terdekat.Setelah itu, pengguna bisa langsung menggunakan layanan T-Cash di merchant-merchant pilihan Telkomsel, seperti McDonald's, The Coffee Bean, Baskin Robbins, Wendy's, Seven Eleven, Cinema XXI, Blanja.com, Gramedia, dan lainnya.Pada saat ini di Jabodetabek TCASH TAP telah diterima di lebih dari 1,000 outlets merchant dan kedepannya akan dikembangkan ke kota-kota lain hingga dapat menjangkau secara nasional.

Beberapa layanan yang ditawarkan oleh T-Cash adalah sebagai berikut :

a) Aktivasi Sebelum bisa menggunakan layanan T-Cash, pelanggan diharuskan untuk melakukan aktivasi terlebih dahulu. Pelanggan yang bisa melakukan aktivasi adalah pelanggan Telkomsel baik yang menggunakan kartu As, kartu Simpati maupun kartu Halo. Untuk melakukan aktivasi, pelanggan Telkomsel cukup mengirimkan SMS dengan format sebagai berikut : Ketik :TCASH(spasi)Nama\#Tgl Lahir\#Nama Ibu Kandung Kirim ke 2828 Contoh : Tcash Alif\#14041980\#Titi Kirim ke 2828

b) Cek Saldo Sebagaimana mobile wallet, layanan T-Cash memberikan kemudahan bagi penggunanya untuk melakukan cek saldo dimanapun pelanggan tersebut berada dan kapanpun pelanggan membutuhkan pengecekan saldo. Untuk melakukan cek saldo, pelanggan TCash cukup mengirimkan SMS dengan format sebagai berikut : Ketik : SalPIN kirim ke 2828

c) Ganti Pin Untuk meningkatkan tingkat keamanan dalam bertransaksi, T-Cash dilengkapi dengan fitur PIN ( Personal Identification Number ). PIN ini digunakan setiap kali pelanggan T-Cash melakukan transaksi Cash in, Cash out, pembelian, pembayaran tagihan serta transfer antar pelanggan T-Cash. Untuk melakukan penggantian pin, pelanggan $\mathrm{T}$-Cash cukup mengirimkan SMS dengan format sebagai berikut : Ketik : CPIN(spasi)PIN Lama(spasi)PIN Baru kirim ke 2828 Contoh : CPIN 121212282828 kirim ke 2828

d) Reset Pin PT. Telkomsel melalui layanan T-Cash ini memberikan fasilitas kepada pelanggan untuk melakukan reset pin. Dengan fasilitas ini diharapkan para pelanggan T-Cash yang lupa akan PIN pribadinya dapat terbantu untuk mendapatkan PIN yang baru, sehingga proses transaksi bisa berlangsung kembali. Reset pin dapat dilakukan di kantor Grapari ( Graha Pari Sraya ) Telkomsel.

e) Cash in Cash in atau disebut dengan deposit, yakni penambahan saldo dalam layanan T-Cash. Pelanggan yang ingin melakukan cash in, membawa uang tunai sejumlah yang diinginkan untuk masuk ke saldo T-Cash pelanggan. Pengisian saldo bisa dilakukan di seluruh cabang Indomaret, GraPari, GeraiHALO dan mitra TCash lainnya.

f) Cash Out Dengan menggunakan fitur Cash Out, pelanggan T-Cash dapat mengambil uang tunai pada 
merchant-merchant TCash. Seperti halnya mesin ATM, di merchant $\mathrm{T}$-Cash, pelanggan bisa mengambil uang tunai yang tersimpan dalam saldo T-Cash. Cash out bisa dilakukan di seluruh cabang Indomaret, GraPari, GeraiHALO dan mitra T-Cash lainnya.

g) Pembelian Pembelian barang / jasa yang dapat dilakukan oleh T-Cash ada beberapa macam, diantaranya adalah sebagai berikut : -

- Pembelian Pulsa Pulsa yang dibeli melewati T-Cash lebih murah apabila dibandingkan dengan pulsa yang dijual di counter-counter pulsa kebanyakan. Karena, harganya sama dengan nominal pulsa yang dibeli, hanya ditambah biaya kirim 1 sms. Untuk melakukan pembelian pulsa, pelanggan T-Cash cukup mengirimkan SMS dengan format sebagai berikut : Ketik:Pulsa(spasi)NoHP(spasi)No minal Pulsa(spasi)PIN Kirim ke 2828 Contoh : Pulsa 08120000000050000123456

- Pembelian Token PLN Prabayar Pelanggan T-Cash yang menggunakan PLN prabayar di rumahnya dapat dengan mudah untuk mendapatkan token PLN prabayar. Sebab, pelanggan tidak perlu repot untuk mendatangi kantor PLN untuk mendapatkan token PLN prabayar, namun pelanggan cukup dengan mengirim SMS dengan format : Pay (spasi) PLNPRA (spasi) NoMeter(spasi)PIN(spasi)NominalToken Kirim ke 2828 Contoh : Pay PLNPRA 1234567890 12345650000 Setelah pelanggan mengirim SMS dengan format seperti diatas maka pelanggan akan menerima SMS balasan berupa nomor seri token PLN prabayar yang langsung bisa dimasukkan ke dalam meteran listrik di rumah pelanggan.

- Pembelian Barang Dengan menggunakan T-Cash, pelanggan dapat berbelanja dengan mudah dan cepat karena tidak perlu menggunakan uang cash. Cukup dengan mengirim SMS dengan format : BUY(Spasi)NAMAMERCHANT(Spasi) HARGA(Spasi)PIN Contoh : BUY PAPARONSPIZZA 5000012345

- Pembelian Barang Online Pelanggan T-Cash juga diberi fitur untuk dapat membeli barang secara Online. Cukup mengirim SMS dengan format : BUY(Spasi)NAMAMERCHANT(Spasi)

HARGA(Spasi)PIN Contoh : BUY TOKOBAGUS.COM 5000012345 Setelah mengirim SMS dengan format seperti diatas, pelanggan T-Cash akan menerima notifikasi yang tercantum padanya nomor referensi. Nomor referensi inilah yang akan dimasukkan ke dalam website beserta nomor MSISDN (Mobile Subscriber Integrated Services Digital Network Number) atau nomor HP pelanggan. Jika berhasil, maka pelanggan T-Cash akan menerima notifikasi keberhasilan transaksi via SMS.

- Pembayaran Tagihan T-Cash juga memberikan kemudahan bagi pelanggannya untuk membayar tagihan bulanan pelanggan untuk pemakaian kartu HALO, PLN Pasca Bayar, dan Telkomvision. Untuk pembayaran tagihan, pelanggan TCash cukup SMS dengan format : - Untuk pembayaran tagihan Kartu HALO Ketik : PAY(spasi)HALO(spasi)No HP(spasi)PIN Kirim ke 2828 Contoh PAY HALO 081100000012345 - Untuk pembayaran tagihan PLN Pasca Bayar Ketik : PAY(spasi)PLN(spasi)NO Pelanggan(spasi)PIN Kirim ke 2828 Contoh :PAY PLN 55555555555512345 - Untuk pembayaran tagihan Telkomvision Ketik : PAY (spasi) TELVIS (spasi)NO ID Produk(spasi)PIN Kirim ke 2828 Contoh : PAY TELVIS 55555555555512345

- Transfer Dengan menggunakan fitur ini, pelanggan akan dipermudah untuk melakukan transfer uang. Tidak perlu lagi untuk pergi ke ATM untuk mengirim uang dan tidak perlu juga untuk memiliki rekening bank. Karena pelanggan T-Cash dapat melakukan transfer uang dengan menggunakan ponsel pelanggan dimana saja pelanggan berada dan kapanpun pelanggan ingin melakukan transfer. Untuk melakukan transfer, pelanggan T-Cash cukup SMS dengan format : Ketik TRF(spasi)Nomor Tujuan(spasi)Nominal(spasi)PIN Kirim ke 2828 Contoh : TRF 0811000000100000282828 3.3. Tipe Pelanggan T-Cash Terdapat 2 macam pelanggan TCash, yaitu :

- Pelanggan Basic Service Pelanggan basic service adalah pelanggan Simpati / kartu As yang melakukan aktivasi melalui SMS. Pelanggan basic service dapat melakukan transaksi T-Cash sampai dengan Rp. 1.000.000,00. Fitur-fitur yang dapat dinikmati oleh pelanggan basic service adalah aktivasi, cek saldo, ganti pin, cash in, pembelian dan pembayaran tagihan.

- Pelanggan Full Service Pelanggan full service adalah pelanggan kartu HALO yang melakukan aktivasi melalui SMS. Pelanggan full service dapat melakukan transaksi T-Cash sampai dengan Rp. 5.000.000,00. Fitur-fitur yang dapat dinikmati oleh pelanggan full service adalah aktivasi, cek saldo, ganti pin, cash in, pembelian, pembayaran tagihan, reset pin, transfer dan cash out. Pelanggan basic service dapat meningkatkan layanannya menjadi pelanggan full service dengan melakukan regristrasi di GraPari Telkomsel terdekat.

keunggulan T-Cash adalah sebagai berikut :

a) Aktivasi T-Cash mudah. Hanya dengan mengirim SMS dengan format TCASH(spasi)Nama\#Tgl Lahir\#Nama Ibu Kandung dan mengirimkannya ke 2828, pelanggan langsung terdaftar sebagai member T-Cash. Proses aktivasi yang cepat dan murah yakni hanya dengan biaya seharga 1x SMS membuat T-Cash menjadi pilihan utama 
pelanggan dalam menikmati layanan digital money di Indonesia.

b) Tarif Layanan Sesuai Tarif SMS Normal Tanpa Biaya Bulanan. Tarif yang diberikan kepada pelanggan TCash dalam menikmati berbagai layanan di dalamnya seperti cek saldo, transfer, pembelian barang / jasa, pembayaran tagihan dan berbagai layanan lain, seharga 1x SMS. Apalagi setiap bulannya pelanggan tidak terkena biaya bulanan, sehingga pelanggan merasa lebih diuntungkan.

c) Uang Elektronik Tersimpan di Handphone (online). Uang elektronik yang tersimpan di Handphone masing-masing pelanggan (tersimpan dalam jaringan T-Cash) membuat pelanggan lebih flexible dalam melakukan transaksi belanja. Karena pelanggan tidak perlu lagi untuk membawa dompet yang tebal ketika berbelanja. Dan keuntungan lain ketika uang elektronik tersimpan secara online adalah lebih aman dari tindak kriminal seperti pencurian.

d) Cek Saldo \& Transaksi Pembayaran Menggunakan Handphone. Berbeda halnya dengan menyimpan uang di Bank conventional, yang mana ketika nasabah ingin melakukan cek saldo maka nasabah harus pergi ke Bank atau setidaknya pergi ke ATM terdekat. Dengan T-Cash, uang yang disimpan oleh pelanggan dalam TCash dapat dicek hanya dengan menggunakan Handphone masingmasing pelanggan. Sehingga, pelanggan tidak perlu susah payah untuk mendatangi ATM atau Bank hanya untuk melakukan cek saldo. Begitu halnya untuk pembayaran tagihan seperti tagihan PLN Prabayar, Telkomvision ataupun tagihan kartu HALO, pelanggan TCash tidak perlu pergi ke masing-masing kantor tagihan tersebut namun cukup membayar tagihannya via SMS dari handphone pelanggan.

e) Isi Ulang Dapat Dilakukan di Merchant-merchant T-Cash. Merchant-merchant T-Cash yang tersebar di seluruh Indonesia mempermudah pelanggan $\mathrm{T}$-Cash untuk melakukan isi ulang. Pelanggan T-Cash tidak perlu bingung untuk mencari tempat isi ulang T-Cash, karena merchant-merchant T-Cash sudah tersebar di seluruh wilayah Indonesia.

f) Compatible Dengan Semua Jenis Handphone. Layanan TCash ini compatible dengan semua jenis handphone, yang penting handphone tersebut bisa melakukan proses SMS. Karena sistem kerja layanan T-Cash banyak yang menggunakan SMS. Sifat yang compatible dengan semua jenis handphone ini memudahkan pelanggan untuk menggunakan layanan T-Cash, sebab pelanggan tidak perlu mencari / membeli handphone dengan spesifikasi yang tinggi / spesifikasi tertentu untuk menggunakan layanan ini. Apalagi dengan sifat yang seperti ini tidak menutup kemungkinan bahwa pelanggan T-Cash tidak hanya akan terdiri dari masyarakat dengan tingkat ekonomi menengah keatas namun juga akan merambah ke masyarakat dengan tingkat ekonomi menengah kebawah.

Aman Dilengkapi Dengan PIN Fitur PIN ( Personal Identification Number ) juga disematkan dalam layanan TCash ini, sehingga membuat tingkat keamanan transaksi pelanggan menjadi semakin tinggi. Karena, sekalipun nanti handphone pelanggan dicuri, saldo pelanggan yang tersimpan dalam jaringan T-Cash masih tetap aman. Sebab, layanan TCash ini tidak hanya memerlukan MSISDN / nomor HP pelanggan namun juga PIN untuk melakukan berbagai transaksinya.

\section{KESIMPULAN}

T-cash adalah suatu layanan digital money di Indonesia yang dapat digunakan pelanggan Telkomsel untuk melakukan transaksi pembelian dan pembayaran secara digital dengan menggunakan ponsel di merchant yang berlogo t-cash. Tcash merupakan layanan digital money yang menggunakan teknologi NFC (Near Field Communication). Dengan Kemudahan yang ditawarkan, pelanggan Telkomsel dapat bertransaksi hanya dengan menempelkan stiker T-cash di toko atau tempat berlogo T-cash. Stiker dapat disematkan di punggung ponsel. NFC di negara Indonesia merupakan salah satu alat yang efisien dalam melakukan transaksi pembayaran. Diharapkan dengan Tcash yang menggunakan teknologi NFC dapat memberikan alternative cara bayar baru sehingga dapat memberikan akses keuangan yang nyaman ke berbagai kalangan masyarakat. Bukan hanya diperkotaan, tetapi juga pedesaan. Termasuk masyarakat yang belum terlayani oleh lembaga keuangan resmi (unbanked).

\section{REFERENSI}

[1]. Fatkhul Maskur 2015. (online) http://industri.bisnis.com/read/20151025/105/485717/te lkomsel-perbarui-t-cash-dengan-teknologi-near-fieldcommunication (diakses Oktober 2017).

[2]. Khoirunnisa 2016.(online) http://selular.id/news/telco/2016/02/sediakan-aplikasinfc-tcash-gak-perlu-stikerlagi/ (diakses Oktober 2017).

[3]. Fauzan Jamaludin 2015. (online) https://www.merdeka.com/teknologi/teknologicanggih-nfc-jadi-keunggulan-tcashtelkomsel.html(diakses Oktober 2017).

[4]. https://digitalpayment.telkomsel.com/faq(diakses Oktober 2017).

[5]. Angga Setiawan 2012. (online) http://elektro.undip.ac.id/el_kpta/wpcontent/uploads/2012/05/L2F007010_MKP.pdf(diakses Oktober 2017).

[6]. Sulistia Endah 2016. (online) https://telko.id/8069/demi-terciptanya-ekosistem-iotindosat-luncurkan-nexthing/ (diakses Oktober 2017).

[7] Dody Ichwana Putra, Wanda Syahputra 2017. (online) http://teknosi.fti.unand.ac.id/index.php/teknosi/article/v iew/290(diakses Oktober 2017). 